\title{
The Primate Subthalamic Nucleus. II. Neuronal Activity in the MPTP Model of Parkinsonism
}

\author{
H. BERGMAN, T. WICHMANN, B. KARMON, AND M. R. DELONG \\ Department of Physiology, The Hebrew University, Hadassah Medical School, Jerusalem, Israel 91010; and Department \\ of Neurology, Emory University, Atlanta, Georgia 30322
}

\section{SUMMARY AND CONCLUSIONS}

1. The neuronal mechanisms underlying the major motor signs of Parkinson's disease were studied in the basal ganglia of parkinsonian monkeys. Three African green monkeys were systemically treated with 1-methyl-4-phenyl-1,2,3,6-tetrahydropyridine (MPTP) until parkinsonian signs, including akinesia, rigidity, and a prominent 4- to 8-Hz tremor, appeared. The activity of neurons in the subthalamic nucleus (STN) and in the internal segment of the globus pallidus (GPi) was recorded before (STN, $n$ $=220$ cells; $\mathrm{GPi}, n=175$ cells $)$ and after MPTP treatment (STN, $n=326$ cells; GPi, $n=154$ cells ).

2. In STN the spontaneous firing rate was significantly increased from $19 \pm 10$ (SD) spikes/s before to $26 \pm 15$ spikes/s after MPTP treatment. Division of STN ncurons recorded after MPTP treatment into cells with rhythmic bursts of discharge occurring at 4-8 $\mathrm{Hz}$ (as defined by autocorrelation analysis) and neurons without $4-$ to $8-\mathrm{Hz}$ periodic activity revealed an even more prominent increase in the firing rate of the 4- to $8-\mathrm{Hz}$ oscillatory neurons.

3. In GPi overall changes in the average firing rate of cells were inconsistent between different animals and behavioral states. However, the average firing rate of the subpopulation of neurons with 4- to $8-\mathrm{Hz}$ periodic oscillatory activity after treatment with MPTP was significantly increased over that of all neurons before MPTP treatment (from 53 to 76 spikes/s, averaged across monkeys).

4. In the normal state the percentage of neurons with burst discharges (as defined by autocorrelation analysis) was $69 \%$ and $78 \%$ in STN and GPi, respectively. After MPTP treatment the percentage of cells that discharged in bursts was increased to $79 \%$ and $89 \%$, respectively. At the same time the average burst duration decreased (from $121 \pm 98$ to $81 \pm 99 \mathrm{~ms}$ in STN and from $213 \pm$ 120 to $146 \pm 134 \mathrm{~ms}$ in GPi) with no significant change in the average number of spikes per burst.

5. Periodic oscillatory neuronal activity at low frequency, highly correlated with tremor, was detected in a large number of cells in STN and GPi after MPTP treatment (average oscillation frequency 6.0 and $5.1 \mathrm{~Hz}$, respectively). The autocorrelograms of spike trains of these neurons confirm that the periodic oscillatory activity was very stable. The percentage of cells with 4- to $8-\mathrm{Hz}$ periodic activity significantly increased from $2 \%$ to $16 \%$ in STN and from $0.6 \%$ to $25 \%$ in GPi with the MPTP treatment.

6 . Neurons discharging with periodic bursts at frequencies between 8 and $20 \mathrm{~Hz}$ (average $14.4 \mathrm{~Hz}$ in STN and $10.5 \mathrm{~Hz}$ in GPi) were also detected more often after MPTP. The autocorrelograms of these neurons showed a high degree of dampening. The percentage of neurons with 8 - to $20-\mathrm{Hz}$ oscillations significantly increased from $0.7 \%$ to $10 \%$ in STN and from $0.6 \%$ to $12 \%$ in GPi after MPTP treatment.

7. The average magnitude and duration of phasic responses (increases and decrease in firing rate) to the application of flexion and extension torque pulses to the elbow tended to be increased after MPTP treatment in both STN and GPi.
8. The duration of extracellularly recorded action potentials significantly increased with the MPTP treatment (from $0.67 \pm 0.1$ to $0.81 \pm 0.2 \mathrm{~ms}$ in STN and from $0.73 \pm 0.1$ to $0.8 \pm 0.1 \mathrm{~ms}$ in $\mathrm{GPi}$ ).

9. Tyrosine hydroxylase immunohistochemistry revealed that the striatum as well as STN and GPi of the MPTP-treated monkeys were virtually devoid of dopaminergic terminals.

10. These results support a model in which dopaminergic denervation of the basal ganglia (possibly including extrastriatal sites) leads to increased tonic and phasic activity in STN and GPi. Increased inhibition of thalamocortical neurons by GPi output may eventually result in akinesia and rigidity, whereas periodic oscillatory activity in the cortico-STN-GPi-thalamic circuitry is possibly involved in the development of parkinsonian tremor.

\section{INTRODUCTION}

Parkinson's disease is characterized by akinesia, rigidity, and tremor at rest at a frequency of $4-8 \mathrm{~Hz}$. The pathological hallmark of this disease is the destruction of dopaminergic nigrostriatal neurons, leading to a decrease in the striatal dopamine content (for instance, Hornykiewicz and Kish 1987). Primates treated with the neurotoxin 1-methyl-4phenyl-1,2,3,6-tetrahydropyridine (MPTP) develop motor behavioral and pathological changes that are very similar to Parkinson's disease (Burns et al. 1983; Jenner et al. 1986; Langston et al. 1984). However, low-frequency parkinsonian tremor is a rather infrequent sign in most primates other than African green monkeys (Bergman et al. 1990; Redmond et al. 1985).

Studies of the neuronal activity in the basal ganglia of MPTP-treated macaques have largely concentrated on changes in "tonic" discharge, i.e., changes of the average firing rates in these structures (Filion and Tremblay 1991; Miller and DeLong 1987), and the changes in the "phasic" responses to peripheral inputs (Filion et al. 1988; Miller and DeLong 1987). In these studies the average firing rate of neurons in the internal segment of the globus pallidus (GPi) was increased, whereas the firing rate in the external segment of the globus pallidus (GPe) was decreased. Responses of pallidal neurons to limb perturbation were more frequent and were increased in magnitude and duration. From these electrophysiological and additional metabolic (Mitchell et al. 1989) and histochemical (Gerfen et al. 1990) studies a model has been developed (Albin et al. 1989; Bergman et al. 1990; DeLong 1990) in which the "direct" and the "indirect" pathway between the striatum and GPi (Wichmann et al. 1994a) are differentially affected by the loss of dopamine: the direct pathway becomes un- 
deractive, whereas the projection to GPe, the first portion of the indirect pathway, becomes overactive, leading to reduced activity along the inhibitory GPe-GPi and GPesubthalamic nucleus (STN) pathways. The changes in the direct pathway and in the two branches of the indirect pathway eventually result in overactivity of GPi and its inhibitory projection to the ventrolateral thalamus (VL). According to this model the neuronal activity in STN in parkinsonism is released from the normal tonic inhibition from GPe. The resulting increased activity of STN may play a pivotal role in the generation of parkinsonism, because akinesia, rigidity, and tremor are ameliorated by lesions (Aziz et al. 1991, 1992; Bergman et al. 1990; Guridi et al. 1993), depolarization block (Benabid et al. 1993; Benazzouz et al. 1993), or pharmacological blockade (Baron et al. 1992; Signore et al. 1993; Wichmann et al. 1990a, 1994b) of STN.

As yet the neuronal activity in STN in MPTP-treated monkeys has not been studied in detail. The only previous study of the neuronal activity in STN of such monkeys examined a rather small number of cells and lacked direct control data from the same animals (Miller and DeLong 1987). The first major aim of the present study was therefore to test more thoroughly the prediction that the tonic firing rate in STN is increased after MPTP treatment.

Although the tonic changes in discharge in the basal ganglia of parkinsonian primates serve at least partially to explain akinesia, bradykinesia, and rigidity, they fail to directly explain tremor. Previous studies attributed tremor in Parkinson's disease to changes in firing of the olivocerebellopontine system, as demonstrated in primates with midbrain lesions with or without the injection of the tremorogenic drug harmaline (DeMontigny and Lamarre 1973; Llinas and Volkind 1973), or to tremor-related rhythmic discharges in VL nucleus. Regarding the latter hypothesis it has been proposed that increased tonic inhibition of VL by GPi output predisposes VL neurons to develop overt oscillatory firing (Jahnsen and Llinas 1984a,b). In MPTPtreated macaques, oscillatory activity in the $12-$ to $14-\mathrm{Hz}$ range in GPi neurons has been reported by several authors (Filion and Tremblay 1991; Miller and DeLong 1987). However, this was an inconsistent finding, and the rhythmic neuronal bursts were generally not accompanied by tremor. Recently a mechanism has been proposed (Pare et al. 1990) that would translate the periodic oscillatory firing at $12-14 \mathrm{~Hz}$ into the $3-$ to $5-\mathrm{Hz}$ burst discharges that have been observed during thalamotomy in parkinsonian patients (Lenz et al. 1988; Ohye et al. 1989).

The relevance of these studies to the understanding of parkinsonian tremor in humans is limited because the animal models used generally lack the pathological and clinical features of the human disease. The recently described African green monkey model of MPTP-induced parkinsonism appears to replicate the human disease more closely than previous models. These primates develop a prominent 3- to 5-Hz tremor (Bergman et al. 1990; Redmond et al. 1985 ), which is similar to that in parkinsonian individuals. A second major aim of the present study was therefore to explore the phasic neuronal activity in STN in MPTPtreated animals of this species.
The STN is the major source of excitatory input to GPi, probably exerting a strong influence on the activity of this nucleus (Hamada and DeLong 1992; Hazrati and Parent 1992; Kitai and Kita 1987). To investigate the effects that altered activity of STN neurons may have on basal ganglia output, and as a baseline for data obtained after lesioning of STN (Wichmann et al. 1994b), the third aim of these experiments was to study the tonic and phasic activity of GPi neurons.

Parts of this study have been reported in abstract form (Bergman et al. 1992; Wichmann et al. 1990b).

\section{METHODS}

Methods that have been described in detail in the companion paper (Wichmann et al. 1994a) or elsewhere (Bergman et al. 1990 ) will be described only briefly here.

\section{Animals and behavioral conditioning}

The same three juvenile African green monkeys (monkeys $A-$ $C$; Cercopithecus aethiops aethiops, weight $3-5 \mathrm{~kg}$ ) that were used in the previous report ( Wichmann et al. 1994a) were also used for the current study. The monkeys were trained in a step tracking and a torque holding task and then were treated systemically with MPTP (see below). Recordings from the basal ganglia were carried out using a parasagittal approach before (Wichmann et al. 1994a) and after MPTP treatment (this report). All experiments were carried out in compliance with the National Institutes of Health Guide for Care and Use of Laboratory Animals.

\section{Recording and data acquisition}

Spontaneous and task-related neuronal discharge was recorded from STN and GPi with conventional electrophysiological methods (as described in Wichmann et al. 1994a). Because after the MPTP treatment the monkeys would no longer perform the step tracking movement in the behavioral task and would not cooperate for an adequate somatosensory examination, this report will focus on the spontaneous activity of neurons as well as on changes in discharge induced by the application of elbow torque pulses.

Tremor amplitude was measured with an accelerometer (Entran Devices, Fairield, NJ) attached to the wrist of the monkeys. The output from the accelerometer was amplified, low-pass filtered $(0-50 \mathrm{~Hz})$, and digitally sampled and stored for off-line power spectral and cross-correlation analysis.

\section{MPTP treatment}

The monkeys were treated systemically with MPTP hydrochloride, (Aldrich, Milwaukee, WI; $0.3-0.4 \mathrm{mg} / \mathrm{kg}$, im) for a total of 9-13 injections over a course of 5-15 days. Each monkey was treated with MPTP until it exhibited moderate to scverc parkinsonian signs. The total amount of MPTP given to each monkey differed slightly (monkey $A: 3.4 \mathrm{mg} / \mathrm{kg}$; monkey $B: 3.9 \mathrm{mg} / \mathrm{kg}$; monkey $C: 3.2 \mathrm{mg} / \mathrm{kg}$ ). During the entire time between the MPTP treatment and the end of the recording sessions, careful observation failed to reveal any signs of recovery.

\section{Data analysis}

To calculate overall waveforms of action potentials, averages of 256 consecutive spikes from each cell sampled at $20 \mathrm{kHz}$ with 25 sampling points per spike were computed. The signal-to-noise ratio of each cell was calculated as the sum of squares of the means divided by the sum of the variances of all sampling points. The polarity of the initial wave of the spike, the duration from the 


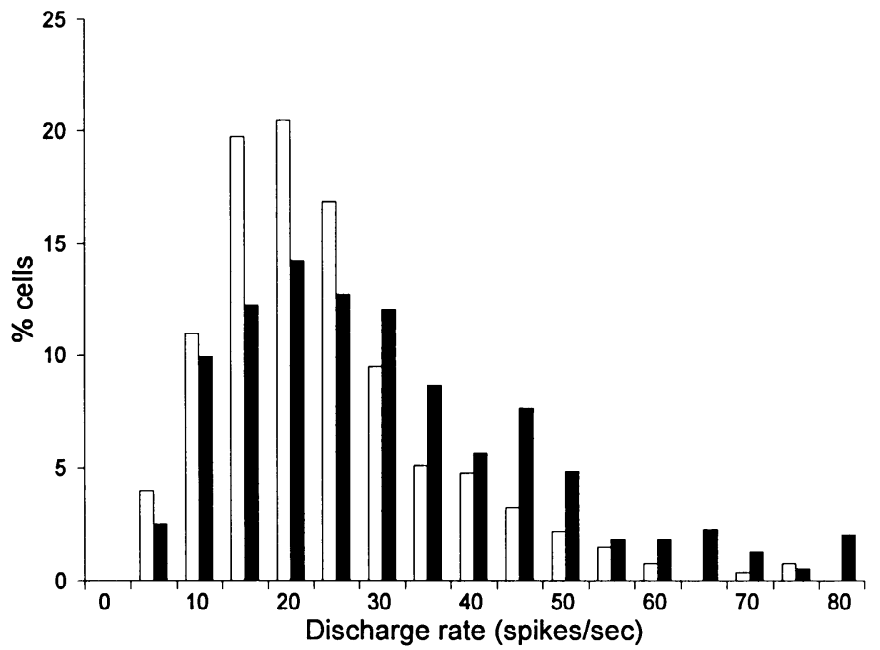

FIG. 1. Distribution of subthalamic nucleus (STN) firing rates before ( $n=220)$ (open bars) and after $(n=324)$ (filled bars) 1-methyl-4-phenyl1,2,3,6-tetrahydropyridine (MPTP) treatments. Data was collected during the pretorque interval and pooled for 3 monkeys.

beginning of the spike to negative and positive peaks, and the duration to zero crossing points were computed. Spike duration was defined as the time from the beginning of a spike to the second crossing of the zero line. Only spikes with an initially negative wave and a signal-to-noise ratio $>5$ were included in the analysis.

The spontaneous firing rate of neurons was calculated during the pretorque period of the torque task (while the monkey was required to keep the manipulandum within a $1.5^{\circ}$ window around the center). Average firing rates were calculated for each individual monkey, for STN and GPi, and for before and after MPTP treatment. Two-tailed $t$ tests were used to test the significance of differences between monkeys in the same state and for individual monkeys before and after MPTP. Data were pooled for all neurons only if no significant difference $(P>0.05)$ between monkeys was found. Relative MPTP-induced changes of the firing rate were calculated for each animal and averaged for all monkeys.

The firing patterns and correlations of neurons were calculated during quiet wakefulness in the primate chair between blocks of trials ("quiet sitting" period). Time interval histograms (TIH), logarithmic TIH ( LgTIH), and autocorrelation and cross-correlation functions were calculated for lag times of 500 (resolution 1 $\mathrm{ms}$ ) and 2,500 $\mathrm{ms}$ (resolution $5 \mathrm{~ms}$ ) for all neurons and for all simultaneously recorded pairs of neurons with acceptable isolation and discrimination quality, as described in the companion paper (Wichmann et al. 1994a). The histograms were smoothed by convolution with a normal curve with variable width (Gaussian moving average). This procedure minimizes the distortion of the histograms in both the time and the frequency domain (Abeles 1982). A normal curve is fitted to the LgTIH and the fit to data, the modal (most common) interval, and the geometric standard deviation of the curve (the degree of scatter around the modal interval) were calculated (Burns and Webb 1976; Paisley and Summerlee 1984). Confidence lines (0.5\% and $99.5 \%$, Abeles 1982 ) for the auto- and cross-correlation functions were computed with the (null) assumption that the number of spikes in any bin of the histogram should fit an independent Poisson distribution (e.g., random firing pattern). Nonrandom discharge of individual cells, or nonindependent firing of pairs of neurons, was assumed if bins in the correlograms were found outside the confidence limits.

A feature-extracting program was used to detect and quantify features in the correlograms that signified nonrandom discharge in individual neurons or nonindependent discharge in pairs of simultaneously recorded cells $(P<0.01)$. Autocorrelograms were classified (see below) as describing a Poisson process, a burst discharge ( 1 initial peak), or periodic oscillatory functions (equally distant multiple peaks). The same algorithm was used to detect and grade periodic oscillatory activity on a scale of $0-10$, using the jitter of the interpeak intervals (maximally $15 \%$ to be considered oscillatory), the number of significant peaks in the studied functions ( $\geq 2$ equidistant peaks to be considered oscillatory), the modulation depths (oscillation amplitude/average firing rate), and the smoothness of the studied function ( see details in Karmon and Bergman 1993). Grade 5 was arbitrarily selected as the minimal grade for the detection of periodic oscillations. If periodic oscillatory activity was detected in the autocorrelograms, the peaks in the TIHs were compared with the oscillation frequency. The grades of oscillatory qualities and the main parameters of periodic activity (e.g., oscillation frequency, number of periodic cycles, and modulation depth) were stored for later analysis. For correlograms with one peak (e.g., autocorrelograms of neurons with burst discharge) the duration and area of the peak (Abeles 1982) was calculated and stored in a data base file. Differences in the proportions of cells in different categories in the normal and in the MPTP-treated state were statistically evaluated by $\chi^{2}$ tests.

Neuronal responses to elbow torque pulses were analyzed as described in Wichmann et al. (1994a). Briefly, the interspike interval data were used to calculate average and SD of discharge rates across trials for the pre- and posttorque epochs. A given cell was classified as responding to the torque pulse if its discharge rate deviated at any time during the posttorque epoch by $>2.5 \mathrm{SD}$ from the mean discharge rate of the pretorque epoch for $>20 \mathrm{~ms}$. Amplitudes and durations of responses were calculated using the onset and offset times of the responses and the average firing rate during the pretorque epoch. Only nonoscillatory cells were included in the analysis of neuronal responses to torque pulses, because strong spontaneous oscillations of the neuronal activity prevented a reliable study of torque-related neuronal responses.

TABLE 1. Spontaneous firing rate of neurons in STN before and after MPTP treatment

After MPTP

Before MPTP

$17.2 \pm 9.0(154)$
$21.6 \pm 11.8(12)$
$22.8 \pm 12.0(54)$

$22.8 \pm 12.0(54)$
4- to $8-\mathrm{Hz}$

Oscillatory neurons

Other neurons

All neurons

Monkey
$A$
$B$
$C$

$34.9 \pm 12.4(40)^{*}$
$38.2 \pm 8.2(4)^{* *}$
$34.9 \pm 12.9(7)^{* *}$
$22.5 \pm 14.0(171)^{*}$
$35.3 \pm 19.8(23)^{* * *}$
$24.1+13.4(49)$

$24.8 \pm 14.4(211)^{*}$
$35.7 \pm 18.1(27)^{* *}$
$25.4 \pm 13.6(56)$

Values are means $\pm \mathrm{SD}$, with number of neurons in parentheses. Oscillatory neurons and oscillation are defined by a feature-extracting algorithm (see METHODS). Data collected during the pretorque epoch of the behavioral task. STN, subthalamic nucleus; MPTP, 1-methyl-4-phenyl-1,2,3,6-tetrahydropyridine. ${ }^{*} P<0.01 ;{ }^{* *} P<0.05$; significant difference from the before MPTP value (2-tailed $t$ test). 


\begin{tabular}{|c|c|c|c|c|}
\hline & \multirow[b]{2}{*}{ Before MPTP } & \multicolumn{3}{|c|}{ After MPTP } \\
\hline & & $\begin{array}{l}\text { 4- to } 8-\mathrm{Hz} \\
\text { Oscillatory neurons }\end{array}$ & Other neurons & All neurons \\
\hline \multicolumn{5}{|c|}{ Monkey } \\
\hline $\begin{array}{l}A \\
B\end{array}$ & $\begin{array}{l}44.2 \pm 14.8(16) \\
50.5 \pm 13.2(21)\end{array}$ & $75.4 \pm 20.4(15)^{*}$ & $\begin{array}{l}50.1 \pm 26.2(37) \\
\text { NA }\end{array}$ & $\begin{array}{l}57.4 \pm 27.1(52) \\
38.8 \pm 13.4(7)\end{array}$ \\
\hline$C$ & $65.0 \pm 15.1(83)$ & $77.1 \pm 25.6(11)^{* *}$ & $62.3 \pm 25.2(38)$ & $65.6 \pm 26.2(49)$ \\
\hline
\end{tabular}

Values are means $\pm \mathrm{SD}$, with number of neurons in parentheses. Oscillatory neurons and oscillation are defined by a feature-extracting algorithm (see METHODS). Because the number of neurons recorded in GPi of monkey $B$ after treatment with MPTP is small, the data obtained from this monkey and marked "NA" are not further broken down. GPi, internal segment of globus pallidus. For other abbreviations, see Table 1 . ${ }^{*} P<0.01 ;{ }^{* *} P<0.05$; significant difference from the before MPTP value (2-tailed $t$ test).

\section{RESULTS}

\section{Data base}

As in the companion paper (Wichmann et al. 1994a), the data base contained different sets of neurons for different parts of the study. Three hemispheres were sampled by 94 penetrations in the normal state, whereas four hemispheres were sampled in 79 penetrations in the post-MPTP period.

Overall, 220 STN cells from the control state and 294 in the post-MPTP period were used for the study of neuronal responses to the application of elbow torque pulses. Firing pattern analysis was carried out in 291 neurons in the normal state and 326 STN neurons from the post-MPTP phase of the experiments. Cross-correlation analysis was carried out for 72 pairs of cells in STN recorded simultaneously with a single electrode in the normal state and 25 neuronal pairs similarly recorded in the post-MPTP state.

In GPi 120 cells from the normal stage and 108 neurons from the post-MPTP stage were used for the study of neuronal responses to the application of torque pulses. Firing pattern analysis was carried out in 175 neurons in the normal state and 154 cells in the post-MPTP state. Cross-correlation analysis was carried out for 18 pairs of GPi neurons in the normal state and 8 pairs recorded in the post-MPTP state.

\section{Behavioral effect of MPTP treatment}

The chronic effects of the MPTP treatment have already been described in detail (Bergman et al. 1990). Briefly, after three to eight injections akinesia developed as the first and most prominent sign of parkinsonism. During the course of injections and the first few days thereafter, the monkeys became more and more akinetic, until they were eventually unable to feed or groom themselves. Several days after the development of akinesia, rigidity and tremor were detected. Low-frequency tremor occurred usually during postural adjustments or states of increased arousal of the monkeys. The amplitude of tremor was often increased just before the onset of movements, but tremor was not observed during movements. Only in a few instances, elbow torque pulses $(0.1 \mathrm{Nm}, 60 \mathrm{~ms})$ were effective in resetting the tremor. In the power spectra of accelerometer recordings of tremor, the fundamental frequency was always $<8 \mathrm{~Hz}$ ( see Bergman et al. 1990 and Fig. 4C).

The parkinsonian symptoms of all three monkeys were stable for the entire recording period $(30,17$, and 27 days, respectively, after the MPTP treatment). Monkey $C$, the most severely affected monkey, died unexpectedly, whereas the remaining two monkeys were used for the third part of this series (Wichmann et al. 1994b).

\section{Waveform of extracellularly recorded action potentials}

The waveforms of extracellularly recorded action potentials (spikes) in STN and GPi had an initial negative wave followed by a smaller positive deflection. Neurons with initial positive spikes, representing $\sim 10 \%$ of recorded spikes, were not included in the analysis.

In both structures the negative peak tended to be larger than the positive peak. The spike duration was $670 \pm 100$ (SD) $\mu \mathrm{S}$ in STN $(n=72)$ and $730 \pm 130 \mu \mathrm{s}$ in GPi $(n=$ $132)$. This difference mainly reflected a longer duration of

TABLE 3. Oscillation frequencies of neuronal activity of single neurons in the basal ganglia of normal and MPTP-treated monkeys

\begin{tabular}{|c|c|c|c|c|c|}
\hline & Total & Oscillatory Cells & $4-8 \mathrm{~Hz}$ & $8-20 \mathrm{~Hz}$ & $>20 \mathrm{~Hz}$ \\
\hline \multicolumn{6}{|l|}{ STN } \\
\hline Before MPTP & 291 & $11(3.8)$ & $6(2.1)$ & $2(0.7)$ & $3(1.0)$ \\
\hline After MPTP & 326 & $89 *(27.3)$ & $53 *(16.3)$ & $34 *(10.4)$ & $2(0.6)$ \\
\hline \multicolumn{6}{|l|}{$\mathrm{GPi}$} \\
\hline Before MPTP & 175 & $9(5.1)$ & $1(0.6)$ & $1(0.6)$ & $7(4.0)$ \\
\hline After MPTP & 154 & $62 *(40.3)$ & $39 *(25.3)$ & $19 *(12.3)$ & $4(2.6)$ \\
\hline
\end{tabular}

Values are numbers of cells, with percentages in parentheses. Neuronal activity was recorded during the quiet sitting state. Oscillatory neurons are defined by the feature-extracting algorithm (see METHODS). Total, total number of cells. Oscillatory cells, number and percentages of all oscillatory neurons. $4-8 \mathrm{~Hz}$, number and percentages of cells with $4-$ to $8-\mathrm{Hz}$ periodic oscillations. $8-20 \mathrm{~Hz}$, number and percentages of cells with 8 - to $20-\mathrm{Hz}$ periodic oscillations. $>20 \mathrm{~Hz}$, number and percentages of cells with oscillation frequency $>20 \mathrm{~Hz}$. For abbreviations, see Tables 1 and $2 .{ }^{*}$ Significant $(P$ $<0.01)$ difference between data obtained before and after MPTP treatment. 


\section{A STN}

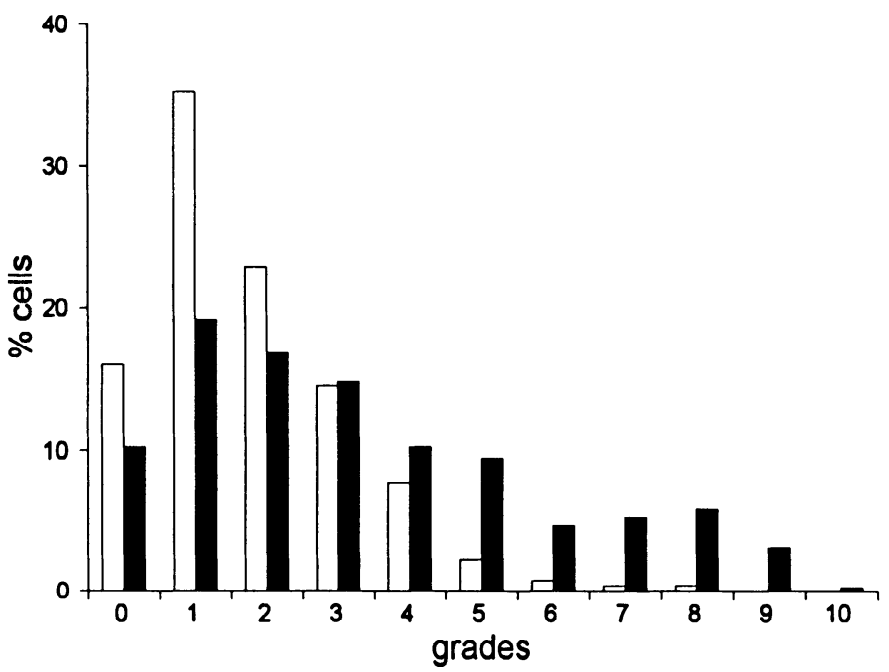

B GPi

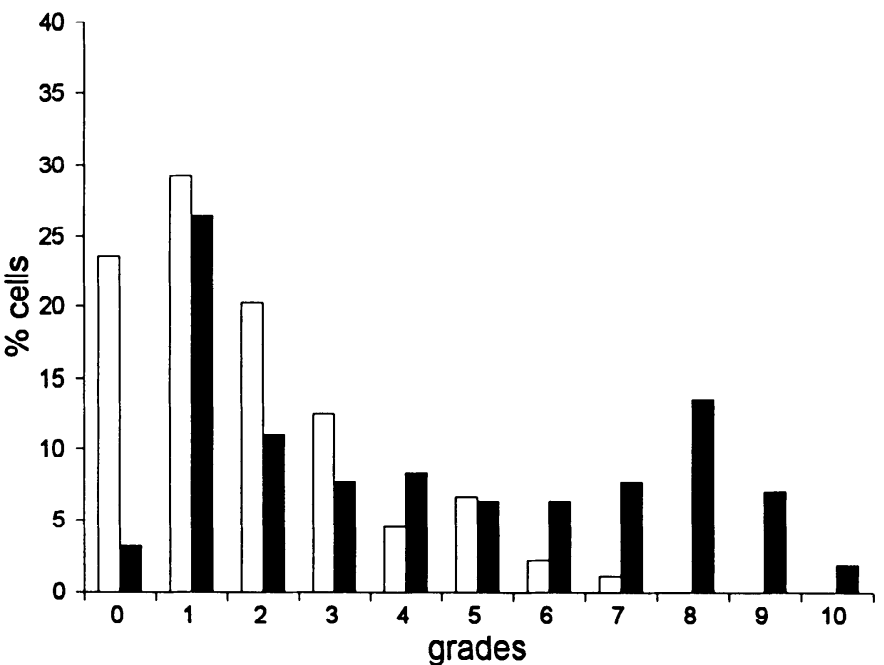

FIG. 2. Distribution of oscillation grades before (open bars) and after (filled bars) MPTP treatment in STN ( $A$ : before MPTP, $n=263$; after MPTP, $n=369$ ) and in internal segment of globus pallidus (GPi) ( $B$ : before MPTP, $n=88$; after MPTP, $n=154$ ). The oscillation grades were calculated using a multifactorial system (see METHODS) in which grades 1-5 describe minimal oscillatory activity. Grades 6-10 describe overt periodic oscillatory activity with increased strength and synchronicity. Only neurons with oscillation grades $>5$ were designated as neurons with periodic oscillatory activity in this study.

the positive wave in GPi neurons. The average duration of the initial negative wave in STN was $280 \pm 40 \mu \mathrm{s}$, whereas the average duration in GPi was $290 \pm 50 \mu \mathrm{s}$.

After the MPTP treatment there was no significant change in the amplitude ratio between positive and negative waves. The spike duration, however, was significantly $(P<0.001, t$ test $)$ increased in STN to $810 \pm 170 \mu \mathrm{s}(n=$ $54)$ and in GPi to $800 \pm 120 \mu \mathrm{s}(n=75)$ after MPTP treatment. In both structures this increase equally affected the duration of negative and positive wave components.

\section{Spontaneous activity-firing rate}

STN. The spontaneous firing rate of STN neurons during the pretorque period in the torque task was significantly increased ( $P<0.01,2$-tailed $t$ test $)$ after MPTP treatment compared with controls (Fig. 1). No significant changes $(P$ $>0.05$ ) were found between monkeys (Table 1 ). The average firing rate in the normal state during the pretorque period was $18.8 \pm 10.3$ spikes $/ \mathrm{s}$ (mean $\pm \mathrm{SD}, n=220$ ) and $25.8 \pm 14.9$ spikes $/ \mathrm{s}(n=294)$ after MPTP treatment.

When 4- to $8-\mathrm{Hz}$ oscillatory cells (see below) from the post-MPTP phase of the experiment were analyzed separately, these cells were found to have a much higher discharge rate than all other cells (Table 1 ).

GPi. For cells in GPi the average firing rates were quite variable between individual monkeys. As in STN, the overall tonic firing rate of GPi neurons after the MPTP treatment tended to be increased, but less consistently ( Table 2).

When 4- to 8-Hz oscillatory cells (see below) cells were analyzed separately, however, a more consistent increase in the average discharge rates of the oscillatory cells in GPi after MPTP treatment emerged (from 53 to 76 spikes/s, averaged across monkeys; Table 2 ).

\section{Spontaneous activity_periodic oscillations}

STN. There were significant changes after MPTP treatment in the firing pattern, most notably the appearance of periodic oscillatory activity. In the normal state very few STN neurons demonstrated periodic oscillatory activity, and if they did, then this activity was relatively weak (grades $<6$; Table 3, Fig. $2 A$ ). After the MPTP treatment $16.3 \%$ of STN neurons demonstrated strong rhythmic bursting activity close to the tremor frequency (grades ranging $\leq 10$; Figs.
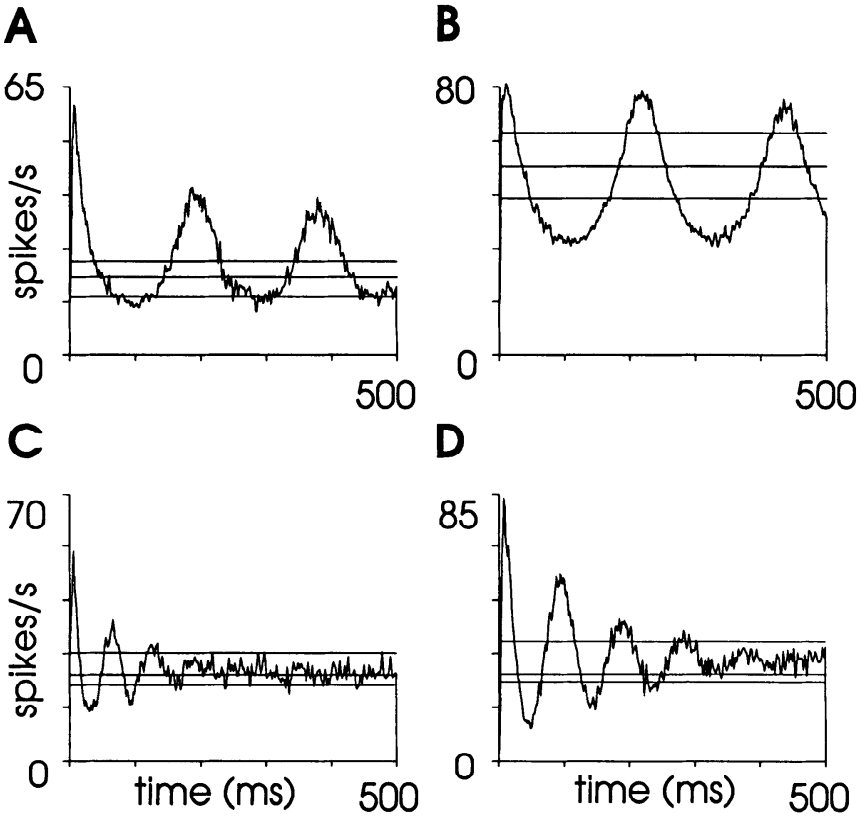

FIG. 3. Examples of autocorrelograms of basal ganglia neurons with periodic oscillatory activity after MPTP treatment. The autocorrelograms were calculated up to a lag time of $500 \mathrm{~ms}$ (bin $=1 \mathrm{~ms}$ ) and smoothed by convolution with a Gaussian curve ( $\sigma=1 \mathrm{~ms}$ ). The oscillation frequencies and grades were calculated with the feature-extracting program ( see METHODS). $A$ : STN neuron with periodic oscillatory activity at $5.3 \mathrm{~Hz}$ (oscillation grade $=9) . B:$ GPi neuron with periodic oscillatory activity at $4.6 \mathrm{~Hz}$ (oscillation grade $=9$ ). $C$ : STN neuron oscillating at $15.6 \mathrm{~Hz}$ (oscillation grade $=8) . D:$ GPi neuron oscillating at $10.7 \mathrm{~Hz}($ oscillation grade $=10)$. 
A

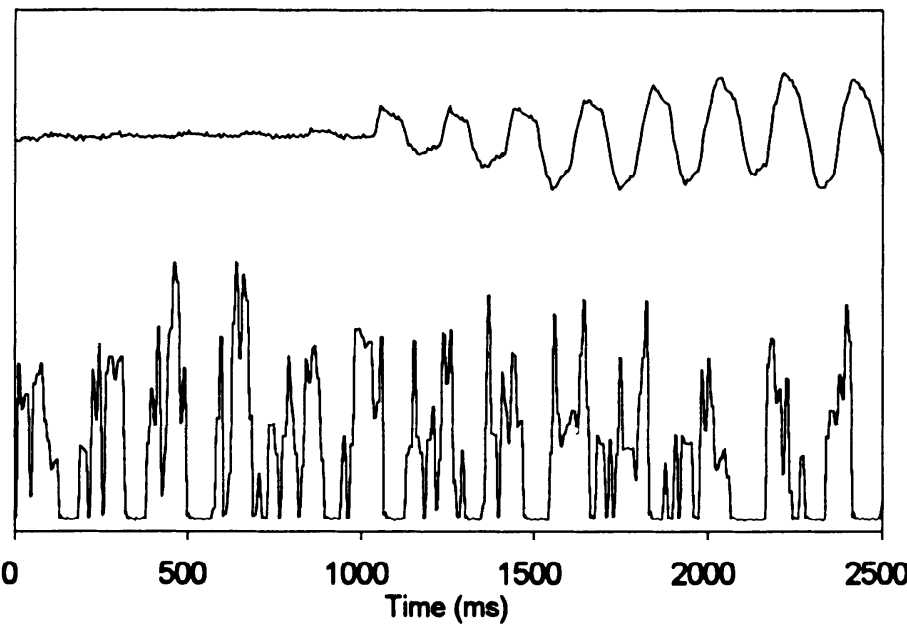

B

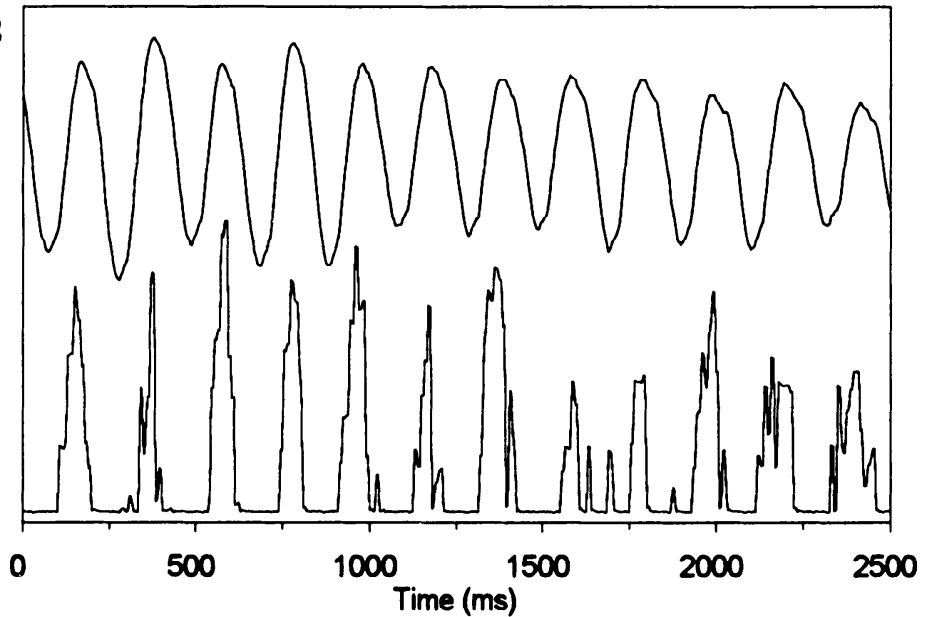

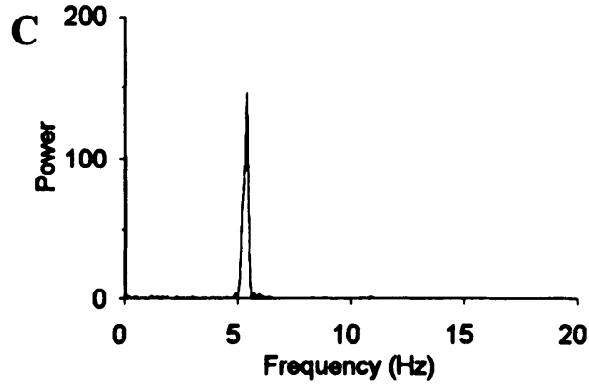
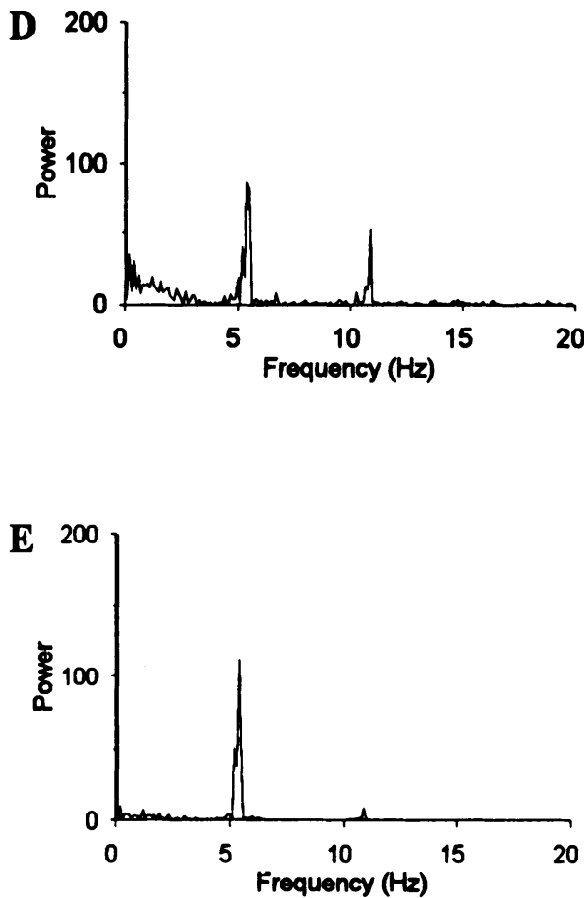

FIG. 4. Neuronal activity in STN coinciding with tremor in MPTP-treated monkey. $A$ and $B$ : examples of simultaneously recorded tremor (accelerometer attached to the left wrist of the monkey, top trace) and overall activity of an STN neuron (through sample and hold integrator, bottom trace). $A$ and $B$ stem from the same recording session and occurred 7 min apart. Sampling frequency: $200 \mathrm{~Hz}$ per channel. Note that in $A$ the periodic oscillatory activity in STN occurred even before the onset of the tremor. $C$ : power spectrum of tremor. $D$ : power spectrum of neuronal activity. $E$ : cross-power spectrum of neuronal activity and tremor. Power and cross-power spectra were calculated from a 40-min data segment, out of which $A$ and $B$ were selected.

$3 A, 4$, and $5 A)$. The average frequency of oscillations of these neurons was $6.0 \pm 0.93 \mathrm{~Hz}$ and the burst duration was $45 \pm 23 \mathrm{~ms}$. The rhythmic neuronal activity was highly correlated with tremor when it was present, but it often appeared even without obvious tremor (Fig. 4). Synchronized oscillatory activity of recorded cells and of the background noise often seemed to increase immediately before the appearance of tremor.

Another $10.4 \%$ of STN cells showed periodic oscillatory activity at higher frequencies (Figs. $3 C$ and $5 A$, Table 3 ), with an average frequency of $14.4 \pm 2.8 \mathrm{~Hz}$. In contrast to the stable 4- to $8-\mathrm{Hz}$ oscillations, autocorrelograms of these higher-frequency oscillators showed dampened oscillatory waves (Fig. $3 C$ ). In neurons with periodic oscillations of $4-8 \mathrm{~Hz}$ the average number of significant peaks in the autocorrelogram was $8.6 \pm 3.7$, whereas it was $4.8 \pm 1.5$ in neurons with oscillatory activity at $8-20 \mathrm{~Hz}$.
The LgTIH of 21 of $89(23.6 \%)$ of the oscillatory neurons in STN showed a second peak corresponding to the interburst interval (Fig. 6, $B$ and $C$ ). Few cells showed an additional third peak (Fig. $6 D$ ); however, the relationship of this peak to the oscillation frequency (as determined from the autocorrelograms) was not consistent.

Cells with oscillatory activity were evenly distributed throughout the entire STN, although they were most often found in its dorsolateral planes (Fig. 7).

GPi. In the normal state only 5\% of cells in GPi demonstrated oscillatory activity, most of them with an oscillation frequency $>20 \mathrm{~Hz}$ ( Table 3). After treatment with MPTP, $25.3 \%$ of neurons in GPi showed strong 4- to $8-\mathrm{Hz}$ oscillatory activity (Figs. $2 B$ and $3 B$; Table 3 ) with an average frequency of $5.1 \pm 0.5 \mathrm{~Hz}$. Higher-frequency periodic oscillations (average $10.5 \pm 1.2 \mathrm{~Hz}$ ) were found in $12.3 \%$ of the neurons (Figs. $3 D$ and $5 B$; Table 3 ). Many (15 of 62 , 


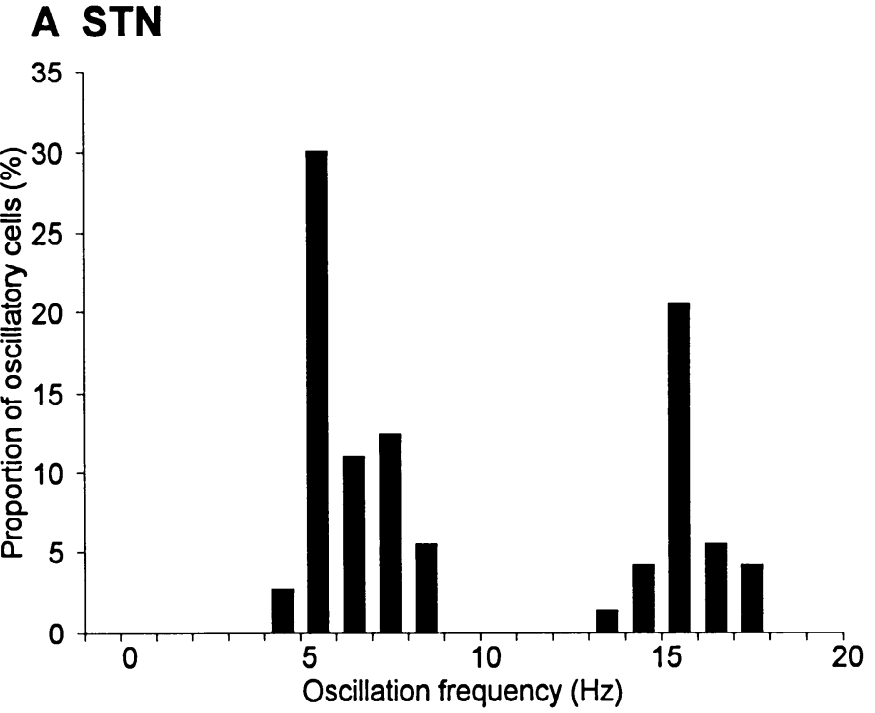

B GPi

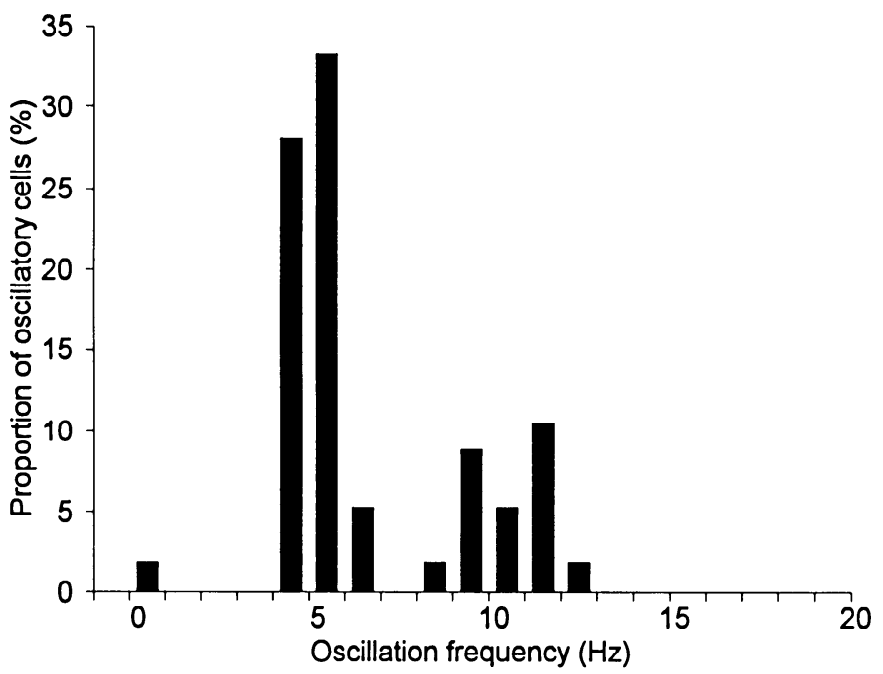

FIG. 5. Distribution of oscillation frequencies of the neuronal activity in the basal ganglia of MPTP-treated monkeys. Data are pooled for the 3 monkeys used in this study. Oscillations were detected and graded by the feature-extracting program. $A$ : oscillation frequencies of STN neurons with periodic activity. All neurons with oscillation grades $>5$ were included $(n=73)$. $B$ : oscillation frequencies of GPi neurons with periodic activity. All neurons with grades $>5$ were included $(n=57)$.

$24.2 \%$ ) of the oscillating neurons showed a second peak in the TIH, but only two (3.2\%) showed a third peak. As in STN, oscillatory cells in GPi were evenly distributed over the entire area of GPi.

\section{Spontaneous activity-nonperiodic burst patterns}

STN. Many of STN cells that did not display periodic oscillatory activity still developed an increased tendency to fire in bursts after the MPTP treatment. In the normal state 197 of $291(68.7 \%)$ of the autocorrelograms of the cells indicated a tendency to discharge in bursts, whereas after MPTP treatment the firing pattern of 258 of 326 (79.2\%) neurons showed this tendency. The average burst duration was significantly reduced from $120.6 \pm 98.5 \mathrm{~ms}(n=182)$ before to $80.7 \pm 99.2 \mathrm{~ms}(n=157)$ after MPTP treatment
$(P<0.01,2$-tailed $\iota$ test $)$. The average number of spikes per burst, as calculated from the average area of the initial peak in the autocorrelograms (Abeles 1982), however, was not significantly changed after the MPTP treatment (normal state: $2.3 \pm 2.2$ spikes per burst; MPTP-treated state: $2.5 \pm$ 2.1 spikes per burst; $P>0.1$ ).

GPi. The firing pattern of GPi neurons was also significantly changed after the MPTP treatment. As in STN, the number of cells with a nonrandom firing pattern was increased from 137 of $175(78.3 \%)$ to 130 of $154(84.4 \%)$ after MPTP treatment. The burst duration was significantly reduced from $212.9 \pm 120.5 \mathrm{~ms}(n=114)$ to $146.3 \pm 134.2$ $\mathrm{ms}(n=64)$, whereas the number of spikes per burst was not significantly changed (burst area: before, $0.88 \pm 0.93$ spikes; after, $0.71 \pm 0.57$ spikes ).

\section{Neuronal responses to elbow torque pulses}

STN. Treatment with MPTP did not significantly change the proportion of responding neurons or the latencies of neuronal responses of nonoscillatory STN neurons ( oscillatory neurons were not included in the analysis; see METHODS). In both the normal and the post-MPTP state, torqueinduced phasic increases in discharge of STN cells were of higher magnitude (Fig. $8 \mathrm{~A}$ ) and shorter duration (Fig. $8 \mathrm{~B}$ ) than phasic decreases in discharge. After MPTP there was a trend toward increased duration and magnitude of neuronal response to torque application (Fig. 8, $A$ and $B$ ), which individually were not statistically significant but led to a significant $\left(P<0.01, \chi^{2}\right.$ test $)$ increase of the total number of spikes per response (response duration $\times$ magnitude; Fig. 8, $C$ and $D)$.

GPi. In contrast to the marked differences in the magnitude between phasic increases and decreases in discharge of STN cells in response to elbow torque pulses, neuronal responses of GPi cells were more symmetric (Fig. 9A). The changes of neuronal responses after MPTP treatment were similar to those reported for STN cells (Fig. 9).

\section{Cross-correlation studies}

STN. Only a small number of pairs of STN neurons were recorded with sufficient quality to allow for cross-correlation analysis. It appeared, however, that the synchronization of neuronal activity between STN cells was not significantly changed by the MPTP treatment. Cross-correlograms of 3 of 25 ( $12 \%$ ) of simultaneously recorded neurons after MPTP treatment indicated synchronous activity (double-sided peak in the cross-correlation function), whereas in the normal state $11.1 \%$ of the recorded pairs had synchronized activity (Wichmann et al. 1994a).

Particularly during phases of tremor, it was evident that many of the neurons recorded as background activity seemed to discharge with synchronized $5-\mathrm{Hz}$ bursts. However, we were unable to record pairs of $5-\mathrm{Hz}$ oscillators with sufficient quality to perform cross-correlation analysis of these cells. On theoretical grounds it is difficult to separate the activity of neighboring cells when they discharge in a tightly synchronized manner (Bergman and DeLong 1992). 

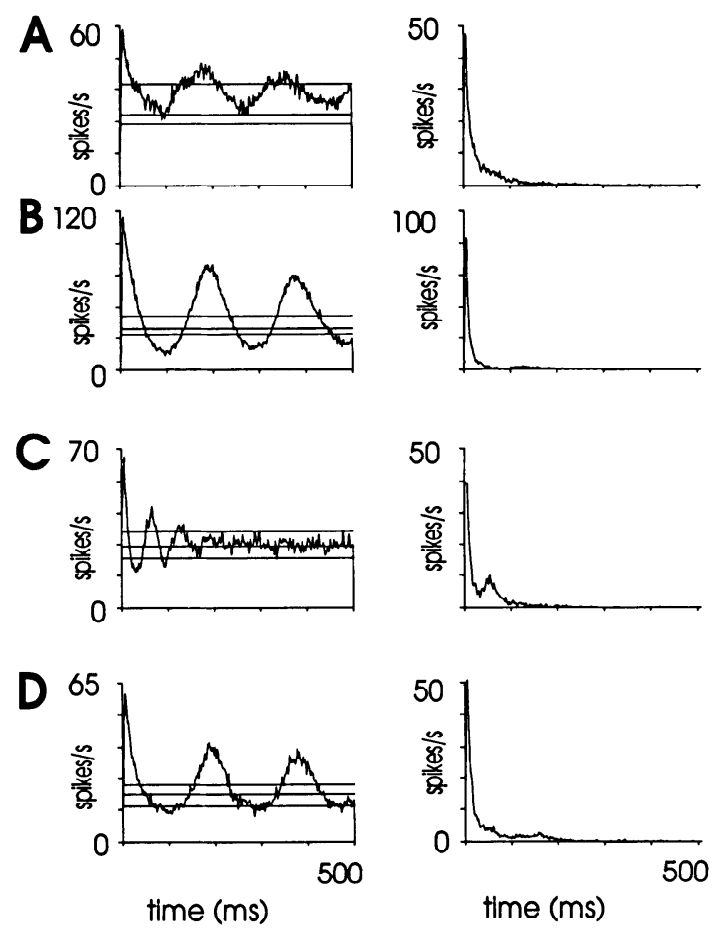

GPi. The cross-correlation functions of simultaneously recorded GPi neurons, computed for 18 pairs of neurons before and 8 pairs of neurons after MPTP, were always indicative of independent firing. The post-MPTP sample may be biased, however, because none of the 16 neurons that could be included in this analysis demonstrated oscillatory activity.

\section{Tyrosine hydroxylase immunohistochemistry}

Sections of the brains of two monkeys (monkeys $A$ and $B$ ) were stained for tyrosine hydroxylase (TH). In the midbrain there were only very few dopaminergic cells in the substantia nigra pars compacta, whereas a considerable number of TH-positive cells persisted in the ventral tegmental area. The striatum, pallidum, and STN were devoid of TH-positive terminals.

\section{DISCUSSION}

Current models of the pathophysiology of parkinsonism emphasize changes of the overall activity in the indirect pathway (Albin et al. 1989; DeLong 1990). These models are based on electrophysiological and metabolic studies in macaques (Filion and Tremblay 1991; Filion et al. 1988; Miller and DeLong 1987; Mitchell et al. 1989) that provide evidence that striatal dopamine loss results in a reduction of tonic neuronal activity in GPe, leading to disinhibition of STN and subsequently to excessive subthalamopallidal drive. This study confirms that there are significant increases in the tonic discharge rate and in phasic responses to passive movements in STN of MPTP-treated monkeys. Furthermore, it demonstrates the emergence of periodic burst discharges in STN and GPi neurons in African green monkeys after treatment with MPTP, which may be relevant for the development of tremor in this primate species and in humans with Parkinson's disease.
FIG. 6. Four examples of firing patterns of STN cells with periodic oscillations of neuronal activity. Each row shows an autocorrelogram (lag time $=500 \mathrm{~ms})$, a time interval histogram $($ TIH $)($ lag time $=500$ $\mathrm{ms}$ ), and a logarithmic $\mathrm{TIH}$ (lag time = $750 \mathrm{~ms}$ ) of an individual cell. A normal curve is fitted to each logarithmic TIH ( see METHODS). $A$ : cell with periodic burst at $5.3 \mathrm{~Hz}$ (grade -8 ) with a single peak in the $\mathrm{TIH}$, corresponding to intraburst firing interval. $B$ : cell having periodic bursts at 5.6 $\mathrm{Hz}($ grade $=9)$, with 2 peaks at the TIH and logarithmic TIH functions. $C$ : cell with periodic bursts at $15.6 \mathrm{~Hz}($ grade $=8)$ with 2 peaks at the TIH and logarithmic TIH functions. $D$ : neuron with periodic bursts at $5.3 \mathrm{~Hz}$ (grade $=10$ ) with 3 peaks in the logarithmic TIH.

\section{Species characteristics of $A$ frican green monkeys}

Species differences between macaques and African green monkeys were already described in the first paper of this series (Wichmann et al. 1994a). In the normal state the average firing rate of neurons in GPi is much lower in green monkeys ( 60 spikes / s; total average of all cells in our study) than in macaques $(\sim 80$ spikes/s; Filion and Tremblay 1991; DeLong et al. 1985). The average firing frequency in STN is also lower in African green monkeys ( 18.8 spikes $/ \mathrm{s}$ ) compared with rhesus monkeys ( 24 spikes/s, DeLong et al. 1985, but see also Matsumura et al. 1992), with the relative frequency ratio between African green monkeys and macaques in STN (76\%) being very close to the ratio in GPi $(67 \%-78 \%)$. Another example of possible species differences is the duration of action potentials. The duration of the negative wave of the extracellularly recorded action potentials of GPi cells reported in the present study $(290 \mu \mathrm{s})$ is somewhat greater than the previously reported duration in rhesus monkeys ( $175 \mu \mathrm{s}$; Mitchell et al. 1987). However, absolute estimates of the duration of extracellularly recorded action potentials are highly dependent on the specifics of the recording method (e.g., filter settings), and therefore comparison between studies may not be valid.

Species differences become even more evident when the response of different monkey species to MPTP is compared. In our experience African green monkeys tend to develop more stable parkinsonian motor signs than MPTPtreated macaques (but see Taylor et al. 1990). The data presented here do not permit judgement of whether the degree of dopaminergic depletion achieved by MPTP treatment in the African green monkeys reported here and the macaques mentioned in the literature is comparable. Thus African green monkeys may simply be more susceptible to the effects of MPTP (Riachi and Harik 1992), depriving them of any chance of recovery, even after doses that would allow recovery in other primates. However, it cannot be 

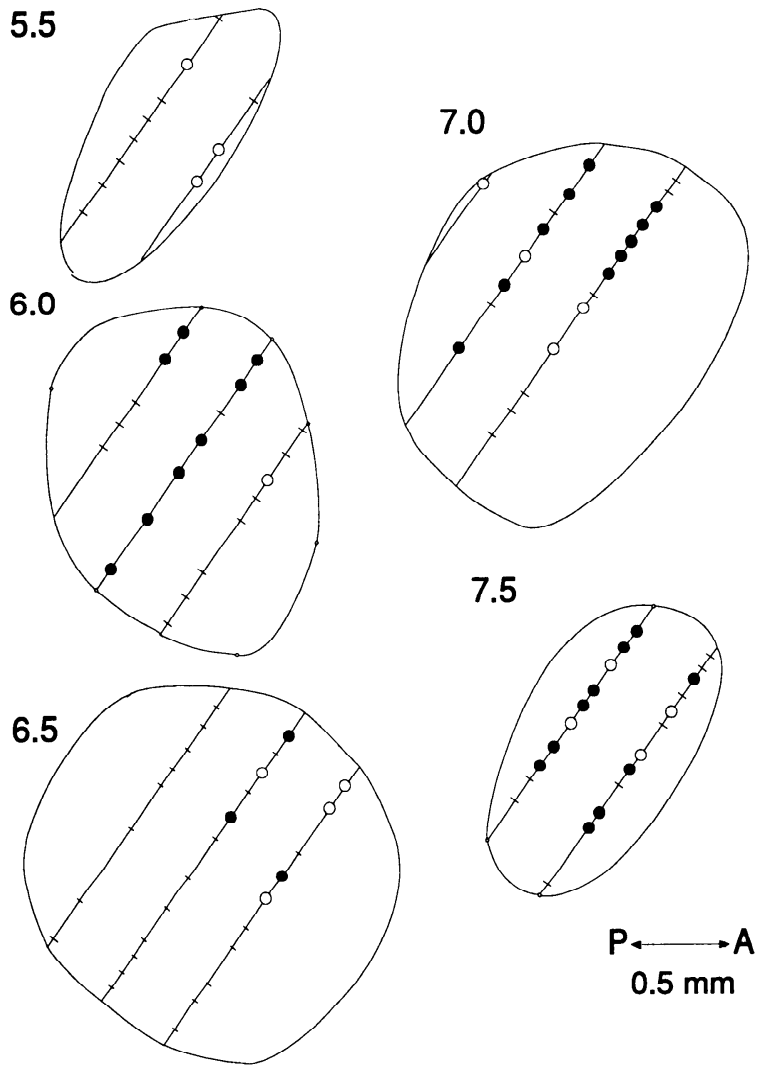

FIG. 7. Distribution of cells with periodic burst discharges in STN of monkey $A$. Filled circles: cells oscillating at $4-8 \mathrm{~Hz}$. Open circles: cells oscillating at 8-20 Hz. Dashes: nonoscillating cells. The electrode penetrations and the estimated locations of the cells were projected on parasagittal sections of STN as used for Fig. 1 in Wichmann et al. (1994a). The actual penetrations were carried out at $0.25 \mathrm{~mm}$ lateral to these planes. See Fig. 1 in Wichmann et al. 1994a also for general orientation of STN with respect to other local structures.

ruled out that MPTP has fundamentally different effects in different monkey species (see also Kopin 1988).

Parkinsonian tremor at low frequencies is not seen in most other primate species (rhesus monkeys: Burns et al. 1983; squirrel monkeys: Langston et al. 1984; marmosets: Jenner et al. 1986; but see Degryse and Colpaert 1986; Gomez-Mancilla et al. 1992). Rhesus monkeys tend to develop a high-frequency action tremor after MPTP treatment, involving the trunk and proximal limbs. In contrast, African green monkeys develop a stable low-frequency tremor quite similar to the tremor seen at rest in human patients with MPTP-induced parkinsonism (Ballard et al. 1985 ), with the notable difference that the distal extremities (wrist and fingers) are most involved in humans, whereas more proximal parts of the limbs and the trunk are involved in the African green monkeys (Bergman et al. 1990; Redmond et al. 1985). MPTP-induced tremor appears therefore to be species dependent, although the exact reasons for these differences are unclear (see also below).

Rhythmic bursting activity in the pallidum has been described in rhesus monkeys after treatment with MPTP. In these monkeys, however, cells were found to discharge at oscillation frequencies of $12-15 \mathrm{~Hz}$ (Filion and Tremblay 1991; Miller and DeLong 1987; Tremblay et al. 1989), with very few neurons oscillating at $5 \mathrm{~Hz}$ (Filion and Tremblay
1991). The present findings of a bimodal distribution of periodic oscillations in STN and in GPi of tremulous MPTP-treated African monkeys, with many neurons oscillating at the tremor frequency, represent an important electrophysiological difference between African green monkeys and macaques, suggesting that rhythmic discharge at $5 \mathrm{~Hz}$ of basal ganglia neurons in African green monkeys may be involved in the development of tremor in this species.

The histochemical analysis of the brains of macaques and African green monkeys after treatment with MPTP also reveals several important differences between these species. Previous anatomic and biochemical studies have demonstrated that the pallidum of macaques contains more monoamine oxidase activity than the pallidum of African green monkeys (Riachi and Harik 1992) and have suggested that the dopaminergic innervation to GPi in macaques is relatively spared after treatment with MPTP (Dacko et al. 1990; Parent et al. 1990; Schneider and Dacko 1991), contrasting with the finding in the present study that GPi was virtually devoid of dopamine after MPTP. The suspected loss of dopamine in GPi of the green monkeys may have particular importance for the development of tremor. GPi is also devoid of dopamine in human patients with parkinsonian tremor, and the degree of dopamine loss in GPi has been reported to correlate to the expression of tremor in humans (Bernheimer et al. 1973).

\section{MPTP-induced changes in properties of the "motor circuit"}

The finding that treatment with MPTP leads to a significant increase of the average discharge rates in STN is consistent with the above mentioned model of parkinsonian pathophysiology. On the basis of previous anatomic and metabolic studies it seems most likely that the increased STN activity reflects a reduction of the inhibitory GPe output. The present study confirms earlier preliminary findings in the macaque monkeys suggesting also that the firing rates in STN of MPTP-treated rhesus monkeys are increased (Miller and DeLong 1987), although the pre- and post-MPTP data in that study were not obtained in the same animals.

In most respects MPTP-induced changes in firing of GPi neurons were very similar to the changes seen in STN, underscoring the close functional relationship between the two nuclei. The changes in average firing rates of GPi neurons in the pretorque periods of this study, however, were less consistent than in previous reports (Filion and Tremblay 1991; Miller and DeLong 1987). Conceivably these differences are related to significant changes of the arousal level between the normal and the post-MPTP state. Arousal is known to have a powerful impact on average firing rates in GPi (DeLong 1969; Detari et al. 1987). This problem is highlighted by the fact that the firing rates measured during periods of quiet wakefulness were consistently lower than the average discharge rates calculated from spike trains during the control period of the torque application task during which the animals were presumably more awake (not shown). The discrepancies with the earlier studies could also be due to species differences ( see above) or to the confounding effects of tremor in the green monkeys used in this study. Last, GPi may suffer a much greater loss of direct 
STN
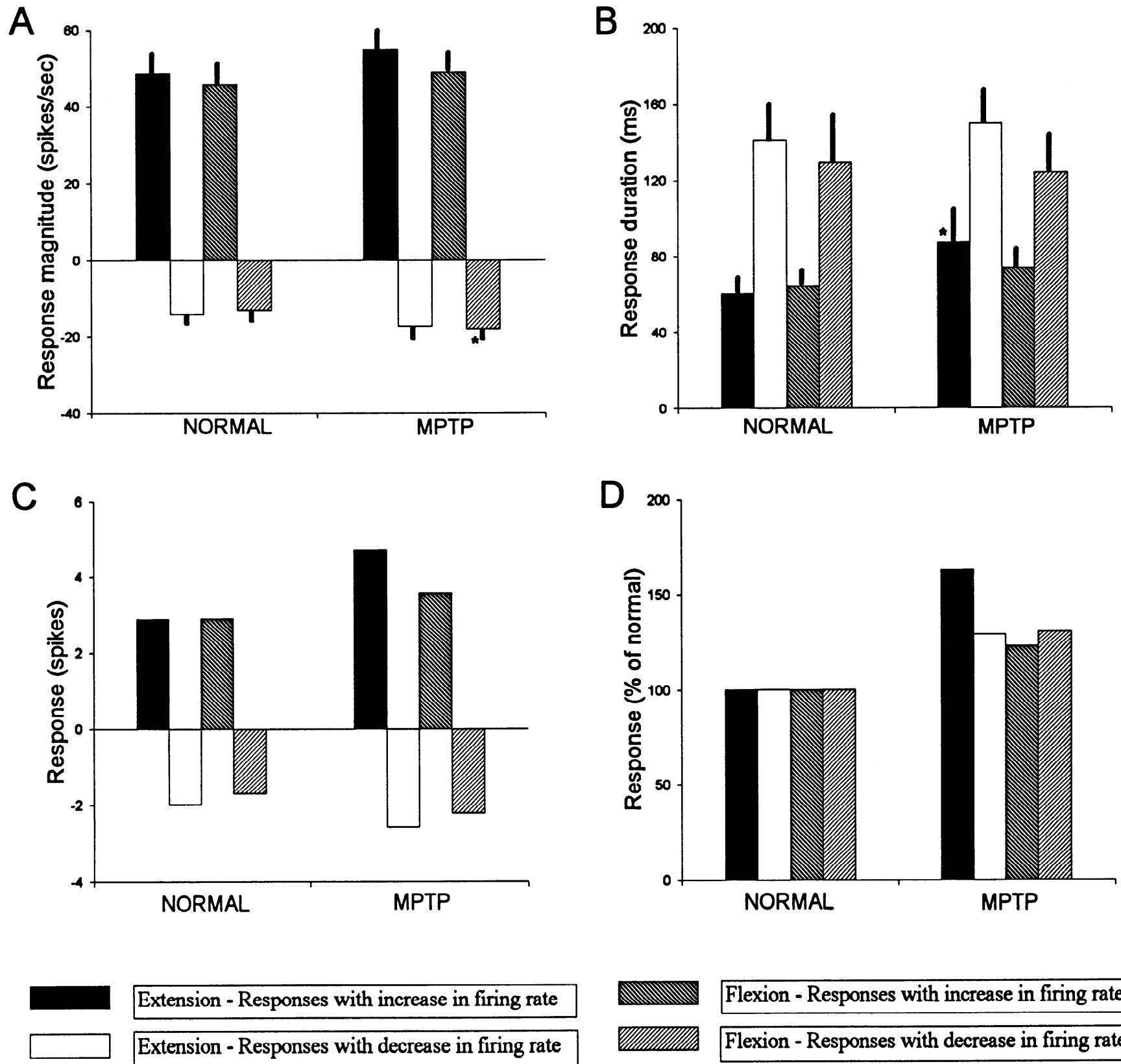

\section{Flexion - Responses with increase in firing rate \\ Flexion - Responses with decrease in firing rate}

FIG. 8. Neuronal responses of STN cells to elbow torquc (poolcd data). Pulses of elbow torque $(0.1 \mathrm{Nm}, 60 \mathrm{~ms})$ were randomly (time and direction) applied to the monkey's elbow. $A$ : response magnitude, calculated as the difference between average firing rate during the response epoch and the mean of the discharge rate at the pretrial epoch. $B$ : duration (milliseconds) of neuronal response. $C$ : total response (spikes) calculated by the multiplication of the response duration and magnitude. $D$ : relative neuronal response. The normal total response for each state is taken as $100 \%$. Bars: averaged values. Superimposed lines: means \pm SE. Asterisk: significant $(P<0.01,2$-tailed $t$ test $)$ difference between the post- and pre-MPTP values. Filled bars: responses to extension torques with increases in discharge rate $(n=43$ responses before and $n=30$ responses after MPTP treatment). Open bars: responses to extension torques with decreases in discharge rate $(n=15$ responses before and $n=19$ responses after MPTP treatment). Leftward-striped bars: responses to flexion torque with increases in discharge rate ( $n=41$ responses before and $n=30$ responses after MPTP treatment ). Rightward-striped bars: responses to flexion torque with decreases in discharge rates $(n=14$ responses before and $n=10$ responses after MPTP treatment).

dopaminergic input in the African green monkey than in macaques (see below). Iontophoretic studies in the rat showed that dopamine increases the firing rate of pallidal neurons (Bergstrom and Walters 1984; Nakanishi et al.
$1985)$. The severe reduction of pallidal dopamine may partially counteract the increase in discharge rates in GPi that would result from loss of dopamine in the striatum. Cells in STN and in GPi that discharged in rhythmic bursts consis- 
tently fired at increased average rates after treatment with MPTP. Discharges patterned in bursts may also elicit stronger postsynaptic effects than nonbursting neuronal discharge at the same firing frequency. Oscillatory cells in STN and GPi may have been particularly susceptible to the effects of MPTP and may have been important in the pathogenesis of parkinsonian motor signs.

The analysis of changes in the phasic responses of cells in STN and GPi to elbow torque application revealed an increase of neuronal responses to torque after MPTP treatment consistent with similar findings in GPe and GPi (Filion et al. 1988; Tremblay et al. 1989; W. C. Miller and M. R. DeLong, unpublished data). Because only nonoscillatory cells could be included in our analysis, likely eliminating the most strongly affected STN and GPi cells, the results probably underestimate the actual increase in neuronal responsiveness. The increase in the magnitude of neuronal response to torque application, the proportion of cells with burst discharges, and the strength of these burst discharges may be due to decreased inhibition of STN from GPe, resulting in an apparent increase in "gain" after MPTP treatment. However, the increased responses may also reflect abnormally strong inputs to the striatum from motor and somatosensory cortical areas, reaching STN via the indirect pathway, or increased phasic input from the corticosubthalamic projection.

\section{Evidence for MPTP-induced changes in membrane properties of individual cells}

Another important feature of the firing pattern observed after treatment with MPTP was the development of a strong rhythmicity of burst discharges in STN and GPi, often tightly linked to simultaneously recorded tremor. However, periodic oscillating neurons in STN and GPi were also demonstrated in the normal state (see also Aldridge and Gilman 1991), in the absence of obvious tremor in the parkinsonian state, and (in GPi) after lesions of STN that ameliorated tremor (Bergman et al. 1990; Wichmann et al. 1994b). This suggests that the rhythmicity of burst discharges in GPi is not simply due to rhythmic proprioceptive inputs propagated via elements of the motor circuit but may result from intrinsic membrane properties of cells in this structure. Spontaneous neuronal oscillations independent of rhythmically changing input have been demonstrated in several in vivo studies (Cordeau et al. 1960; Lamarre and Joffroy 1979) and in thalamic neurons of human parkinsonian patients (Albe-Fessard et al. 1966; Ohye et al. 1974). Our finding of a second family of oscillatory neurons discharging with dampened oscillations at higher frequency in STN and GPi resembles findings in in vitro studies where a bimodal distribution of oscillation frequencies (5-6 and 9-10 Hz) was found (inferior olive: Llinas and Yarom 1981a,b; thalamus: Jahnsen and Llinas $1984 a, b)$. Spontaneous oscillations of the firing pattern of pallidal cells at frequencies of $4-6 \mathrm{~Hz}$ has also been demonstrated in slices of the guinea pig pallidum (Nambu and Llinas 1990), whereas $10-\mathrm{Hz}$ oscillations were found in carlier studies in a slice preparation of the rat pallidum ( $\mathrm{Na}-$ kanishi et al. 1985). The prolongation of the duration of action potentials recorded in STN and in GPi after the
MPTP treatment is further evidence for the fact that the membrane properties of these cells are altered by treatment with MPTP. The duration of extracellularly recorded spikes is identical to that of intracellularly recorded action potentials (Terzuolo and Araki 1961). Changes in the duration of the extracellularly recorded spikes, therefore, most likely reflect changes in the duration of action potentials of the recorded neurons, which are largely dependent on membrane properties of individual neurons.

Oscillatory bursting in STN and in GPi of our animals may have been secondary to tonic disinhibition of both structures from GPe after loss of dopamine in the striatum (see above) or to a direct dopaminergic denervation of STN or GPi. As for the prolongation of the action potential duration, it has previously been shown that activation of dopamine receptors may lead to an increase of the potassium conductance (Drukarch et al. 1990; Einhorn and Oxford 1993; Roeper et al. 1990; Vallar and Meldolesi 1989), suggesting that MPTP-induced loss of dopamine in STN and in GPi may conversely slow down the repolarization process, resulting in prolonged action potentials. The hypothesis that loss of dopamine in extrastriatal basal ganglia structures may contribute to the development of parkinsonian tremor hinges on the presence of dopamine in these structures under normal conditions and on the vulnerability of this dopaminergic innervation to MPTP treatment. Several studies have demonstrated a significant dopaminergic innervation of GPi (Lavoie et al. 1989; Parent and Smith 1987), whereas the existence of a dopaminergic innervation of STN in primates is still debated. Dopaminergic innervation of STN has been demonstrated in rats (Brown et al. 1979; Campbell et al. 1985), cats (Meibach and Katzman 1979; Rinvik et al. 1979), and cynomolgus monkeys (Rinvik et al. 1979), but was not detected in STN of squirrel monkeys (Lavoie et al. 1989). The histologic analysis of our monkeys revealed that there was very little dopamine remaining in STN and GPi after the MPTP treatment; however, baseline data concerning the presence of dopamine under untreated conditions are obviously lacking ( see also Riachi and Harik 1992).

\section{Consequences of altered basal ganglia output}

On the basis of the evidence cited above, changes in tonic basal ganglia output may lead to inhibition in VL. Increased overall inhibition of thalamocortical neurons may result in a lower degree of activation of precentral motor areas during attempted movements. In addition, increased output from the basal ganglia-thalamocortical circuitry in response to proprioceptive inputs may inappropriately signal excessive movement or velocity to precentral motor areas, leading to a slowing or premature arrest of ongoing movements, clinically described as bradykinesia and akinesia. The abnormal phasic responses within the basal ganglia (Filion et al. 1988; Miller and DeLong 1987) may be responsible for the increase of long-latency reflexes that has been described in humans (Tatton and Lee 1975).

Previous models of tremor have placed the origin of the rhythmic neuronal activity outside the basal ganglia, e.g., in the inferior olive or thalamocortical circuits. These schemes are based on previous experimental models of tremor in 
$\mathrm{GPi}$
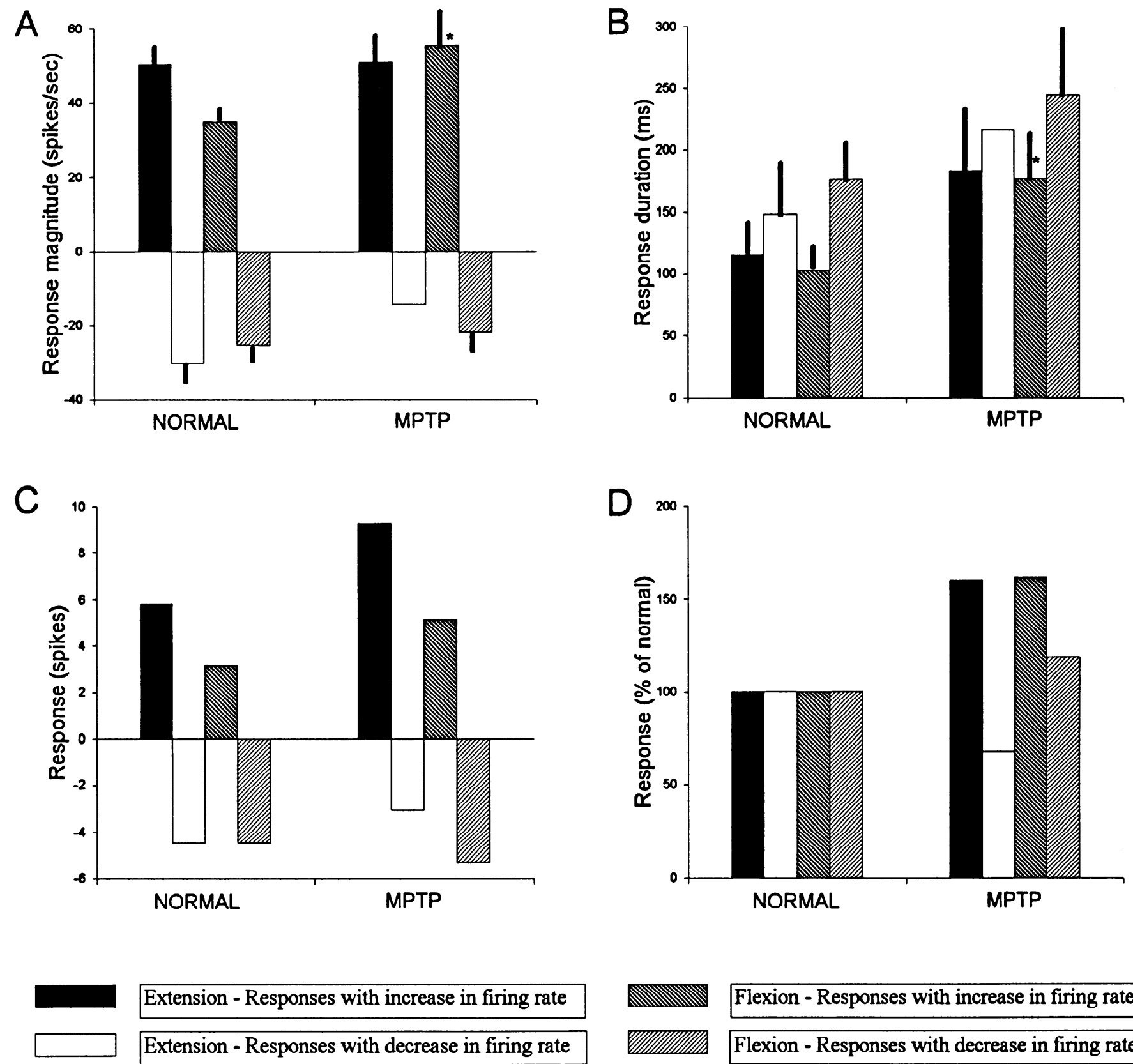

\section{Extension - Responses with increase in firing rate}

Extension - Responses with decrease in firing rate

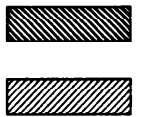

Flexion - Responses with decrease in firing rate

FIG. 9. Average responses of GPi cells to elbow torque (pooled data). Pulses of elbow torque $(0.1 \mathrm{Nm}, 60 \mathrm{~ms})$ were randomly (time and direction ) applied to the monkey's elbow. $A$ : response magnitudes, calculated as the difference between average firing rate during the response epoch and the mean of the discharge rate at the pretrial epoch. $B$ : duration (milliseconds) of neuronal response. $C$ : total response (spikes) calculated by the multiplication of the response duration and magnitude. $D$ : relative ncuronal response. The normal total response for each state is taken as $100 \%$. Bars: averaged values. Superimposed lines: means \pm SE. Asterisk: significant $(P<0.01,2$-tailed $t$ test $)$ difference between the post- and pre-MPTP values. Filled bars: responses to extension torques with increases in discharge rate $(n=18$ responses before and $n=11$ responses after MPTP treatment). Open bars: responses to extension torques with decreases in discharge rate $(n=5$ responses before and $n=1$ response after MPTP treatment). Leftward-striped bars: responses to flexion torque with increases in discharge rate ( $n=16$ responses before and $n=11$ responses after MPTP treatment). Rightward-striped bars: responses to flexion torque with decreases in discharge rates $(n=5$ responses before and $n=4$ responses after MPTP treatment).

animals, which most often used a combination of lesions (e.g., of the midbrain tegmentum) and tremorogenic drugs (Harmaline). In these animals oscillatory neuronal dis- charge that was related to tremor was found in the inferior olive and in the thalamus (DeMontigny and Lamarre 1973; Deschenes et al. 1984; Llinas and Volkind 1973). Tremor- 
related oscillatory activity changes were also detected in the thalamus of human parkinsonian patients (Lenz et al. 1988; Ohye et al. 1974, 1989). Our finding of low-frequency periodic bursts in the basal ganglia, highly correlated with tremor, makes it possible that the basal ganglia are more directly involved in the generation of tremor than previously thought. Conceivably oscillatory basal ganglia output may drive oscillatory activity in neurons in VL that are already more prone to develop rhythmic bursts because their membrane potential is lowered by the overall increased inhibition by GPi output under parkinsonian conditions. In view of these findings a thalamic filter mechanism (Pare et al. 1990) that translates the high-frequency oscillations found in the basal ganglia of macaques (Filion et al. 1988; Miller and DeLong 1987) into low-frequency clinical tremor is unnecessary. Rather, all parkinsonian signs may arise from a single pathophysiological defect, the reduced dopaminergic innervation and the resulting tonic and phasic changes of neuronal discharge in the basal ganglia.

We thank C. A. Kitt for assistance with the immunohistochemistry and the histology and L. H. Rowland for technical assistance.

This research was supported by National Institute of Neurological Disorders and Stroke Grant 5-ROI-NS-15417-14 and by an endowment fund for basic research in the life sciences: Charles A. Revson Foundation, administrated by the Israeli Academy of Sciences and Humanities.

Address for reprint requests: H. Bergman, Dept. of Physiology, The Hebrew University, Hadassah Medical School, P.O. Box 1172, Jerusalem, Israel 91010.

Received 1 April 1993; accepted in final form 22 March 1994.

\section{REFERENCES}

ABELES, M. Quantification, smoothing, and confidence limits for singleunits' histograms. J. Neurosci. Methods 5: 317-325, 1982.

Albe-Fessard, D., Guiot, G., Lamarre, Y., AND Arfel, G. Activation of thalamocortical projections related to tremorogenic processes. In: The Thalamus, edited by D. P. Purpura and M. D. Yahr. New York: Columbia Univ. Press, 1966, p. 237-253.

Albin, R. L., Young, A. B., AND Penney, J. B. The functional anatomy of basal ganglia disorders. Trends Neurosci. 12: 366-375, 1989.

ALDRIDGE, J. W. AND GILMAN, S. The temporal structure of spike trains in primate basal ganglia: afferent regulation of bursting demonstrated with precentral cerebral cortical ablation. Brain Res. 543: 123-128, 1991.

Aziz, T. Z., Peggs, D., Sambrook, M. A., And Crossman, A. R. Lesion of the subthalamic nucleus for the alleviation of 1-methyl-4-phenyl1,2,3,6-tetrahydropyridine (MPTP)-induced parkinsonism in the primate. Movement Disorders 6: 288-293, 1991.

Aziz, T. Z., Peggs, D., Sambrook, M. A., and Crossman, A. R. Subthalamic nucleotomy alleviates parkinsonism in the 1-methyl-4-phenyl1,2,3,6-tetrahydropyridine (MPTP)-exposed primate. Br. J. Neurosurg. 6: 575-582, 1992.

Ballard, P. A., Tetrud, J. W., and Langston, J. W. Permanent human parkinsonism due to 1-methyl-4-phenyl-1,2,3,6-tetrahydropyridine (MPTP): seven cases. Neurology 35: 949-956, 1985.

BARON, M. S., WichmanN, T., AND DeLoNG, M. R. Inactivation of sensorimotor territory in the internal pallidum reverses parkinsonian signs in MPTP-treated monkeys. Soc. Neurosci. Abstr. 18: 693, 1992.

Benabid, A. L., Pollak, P., Gross, C., Hoffman, D., Benazzouz, A., Gao, D. M., Laurent, A., Gentil, M., And Feuerstein, C. Stimulation of subthalamic nucleus acutely changes clinical status in Parkinson's disease. Soc. Neurosci. Abstr. 19: 1052, 1993.

Benazzouz, A., Gross, C., Feger, J., Boraud, T., and Bioulac, B. Reversal of rigidity and improvement in motor performance by subthalamic high frequency stimulation in MPTP treated monkeys. Eur. $J$. Neurosci. 5: 382-389, 1993.

Bergman, H. ANd DeLong, M. R. A personal computer-based spike de- tector and sorter: implementation and evaluation. J. Neurosci. Methods 41: 187-197, 1992.

BERgMan, H., KaRMON, B., WichmanN, T., AND Delong, M. R. Tremor in the MPTP treated primates is associated with low frequency neuronal oscillations. IBAGS IV Abstr. 7, 1992.

Bergman, H., Wichmann, T., AND DeLong, M. R. Reversal of experimental parkinsonism by lesions of the subthalamic nucleus. Science Wash. DC 249: 1436-1438, 1990.

BERGSTROM, D. A. AND WALTERS, J. R. Dopamine attenuates the effect of GABA on single unit activity in the globus pallidus. Brain Res. 310 : 23-33, 1984.

Bernheimer, H., Birkmayer, W., Hornykiewicz, O., Jellinger, K., ANd Seitelberger, F. Brain dopamine and the syndromes of Parkinson and Huntington. J. Neurol. Sci. 20: 415-455, 1973.

Brown, L. L., Markman, M. H., Wolfson, L. I., Dvorkin, B., WARNER, C., AND KATZMAN, R. A direct role of dopamine in the rat subthalamic nucleus and an adjacent intrapeduncular area. Science Wash. DC 206: 1416-1418, 1979.

Burns, B. D. AND WEBB, A. C. The spontaneous activity of neurones in the cat's cerebral cortex. Proc. R. Soc. Lond. B Biol. Sci. 194: 211-223, 1976.

Burns, R. S., Chiueh, C. C., Markey, S. P., Ebert, M. H., Jacobowitz, D. M., AND KoPIN, I. J. A primate model of parkinsonism: selective destruction of dopaminergic neurons in the pars compacta of the substantia nigra by N-methyl-4-phenyl-1,2,3,6-tetrahydropyridine. Proc. Natl. Acad. Sci. USA 80: 4546-4550, 1983.

CAMPbell, G. A., EckardT, M. J., AND Weight, F. F. Dopaminergic mechanisms in subthalamic nucleus of rat: analysis using horseradish peroxidase and microiontophoresis. Brain Res. 333: 261-270, 1985.

Cordeau, J. P., Gybels, J., Jasper, H., ANd Poirier, L. J. Microelectrode studies of single unit discharge in the sensorimotor cortex. Investigations in monkeys with experimental tremor. Neurology 10: 591-600, 1960.

Dacko, S., Smith, M. G., AND Schneider, J. S. Immunohistochemical study of pallidal complex in symptomatic and asymptomatic MPTP treated monkeys, normal human and Parkinson's disease patients. Soc. Neurosci. Abstr. 16: 428, 1990.

Degryse, A. D. AND ColPaERT, F. C. Symptoms and behavioral features induced by 1-methyl-4-phenyl-1,2,3,6-tetrahydropyridine (MPTP) in an old java monkey [Macaca cynomolgus fasicularis (Raffles)]. Brain Res. Bull. 16: 561-571, 1986.

DELONG, M. R. Activity of pallidal neurons in the monkey during movement and sleep (Abstract). Physiologist 12: 207, 1969.

DELONG, M. R. Primate models of movement disorders of basal ganglia origin. Trends Neurosci. 13: 281-285, 1990.

Delong, M. R., Crutcher, M. D., AND Georgopoulos, A. P. Primate globus pallidus and subthalamic nucleus: functional organization. $J$. Neurophysiol. 53: 530-543, 1985.

DEMONTIGNY, J. AND LAMARRE, Y. Rhythmic activity induced by harmaline in the olivo-cerebello-bulbar system of the cat. Brain Res. 53: 81-95, 1973.

Deschenes, M., Paradis, M., Roy, J. P., AND Steriade, M. Electrophysiology of neurons of lateral thalamic nuclei in cat: resting properties and burst discharge. J. Neurophysiol. 51: 1196-1219, 1984.

Detari, L., Juhasz, G., AND Kukorelli, T. Neuronal firing in the pallidal region: firing patterns during sleep-wakefulness cycle in cat. Electroencephalogr. Clin. Neurophysiol. 67: 159-166, 1987.

DRUKARCH, B., SChEPENS, E., AND Stoof, J. C. Muscarinic receptor activation attenuates D2 dopamine receptor mediated inhibition of acetylcholine release in rat striatum: indications for a common signal transduction pathway. Neuroscience 37: 1-9, 1990.

EINHORN, L. C. AND OXFORD, G. S. Guanine nucleotide binding proteins mediate D2 dopamine receptor activation of a potassium channel in rat lactotrophs. J. Physiol. Lond. 462: 563-578, 1993.

FILION, M. AND TREMBLAY, L. Abnormal spontaneous activity of globus pallidus neurons in monkeys with MPTP-induced parkinsonism. Brain Res. 547: 142-151, 1991.

Filion, M., Tremblay, L., AND Bedard, P. J. Abnormal influences of passive limb movement on the activity of globus pallidus neurons in parkinsonian monkeys. Brain Res. 444: 165-176, 1988.

Gerfen, C. R., Engber, T. M., Mahan, L. C., Susel, Z., Chase, T. N., MONSMA, F. J., JR., AND SIBLEY, D. R. D1 and D2 dopamine receptorregulated gene expression of striatonigral and striatopallidal neurons. Science Wash. DC 250: 1429-1432, 1990. 
Gomez-Mancilla, B., Latulippe, J. F., Boucher, R., and Bedard, P. J. Effect of ethosuximide on rest tremor in the MPTP monkey model Movement Disorders 7: 137-141, 1992.

Guridi, J., Luguin, M. R., Herrero, M. T., Guillen, J., AND Obeso, J. A. Antiparkinsonian effect of subthalmotomy in MPTP-exposed monkeys (Abstract). Movement Disorders 8: 415, 1993.

Hamada, I. AND DeLong, M. R. Excitotoxic acid lesions of the primate subthalamic nucleus result in reduced pallidal neuronal activity during active holding. J. Neurophysiol. 68: 1859-1866, 1992.

HAZRATI, L. N. AND PARENT, A. Convergence of subthalamic and striatal efferents at pallidal level in primates: an anterograde double labeling study with biocytin and PHA-L. Brain Res. 569: 336-340, 1992.

HORNYKIEWICZ, O. AND KISH, S. J. Biochemical pathophysiology of Parkinson's disease. Adv. Neurol. 45: 19-34, 1987.

JAHNSEN, H. AND LLINAS, R. Electrophysiological properties of guinea-pig thalamic neurones: an in vitro study. J. Physiol. Lond. 349: 205-226, 1984a.

JAHNSEN, H. AND LLINAS, R. Ionic basis for the electroresponsiveness and oscillatory properties of guinea-pig thalamic neurones in vitro. J. Physiol. Lond. 349: 227-247, 1984b.

JenNer, P., Rose, S., Nomoto, M., ANd Marsden, C. D. MPTP-induced parkinsonism in the common marmoset: behavioral and biochemical effects. In: Advances in Neurology, edited by M. D. Yahr and K. J. Bergmann. New York: Raven, 1986, vol. 45, p. 183-190.

KARMON, B. AND BERGMAN, H. Detection of neuronal periodic oscillations in the basal ganglia of normal and parkinsonian monkeys. Isr. $J$. Med. Sci. 29: 570-579, 1993.

KitAI, S. T. AND KITA, H. Anatomy and physiology of the subthalamic nucleus: a driving force of the basal ganglia. In: The Basal Ganglia. II. Structure and Function: Current Concepts, edited by M. B. Carpenter and A. Jayaraman. New York: Plenum, 1987, p. 357-373.

KOPIN, I. J. MPTP toxicity: implications for research in Parkinson's disease. Annu. Rev. Neurosci. 11: 81-96, 1988.

LAMARRE, Y. AND JOFFROY, A. J. Experimental tremor in monkey: activity of thalamic and precentral cortical neurons in the absence of peripheral feedback. Adv. Neurol. 24: 109-122, 1979.

Langston, J. W., Forno, L. S., Rebert, C. S., AND IRwin, I. Selective nigral toxicity after systemic administration of 1-methyl-4-phenyl1,2,3,6-tetrahydropyrine (MPTP) in the squirrel monkey. Brain Res. 292: $390-394,1984$.

Lavoie, B., Smith, Y., AND PaRent, A. Dopaminergic innervation of the basal ganglia in the squirrel monkey as revealed by tyrosine hydroxylase immunohistochemistry. J. Comp. Neurol. 289: 36-52, 1989.

Lenz, F. A., TAsker, R. R., Kwan, H. C., Dostrovsky, J. O., AND Murphy, J. T. Single unit analysis of the human thalamic ventral nuclcar group: correlation of thalamic "tremor cells" with the 3-6 Hz component of parkinsonian tremor. J. Neurosci. 8: 754-764, 1988.

LlinAS, R. R. AND VolkIND, R. The olivo-cerebello system: functional properties as revealed by harmaline induced tremor. Exp. Brain Res. 18: 69-87, 1973.

LLINAS, R. R. AND YAROM, Y. Electrophysiology of mammalian inferior olivary neurons in vitro. Different types of voltage dependent ionic conductance. J. Physiol. Lond. 315: 549-567, 1981 a.

Llinas, R. R. AND YaROM, Y. Properties and distribution of ionic conductances generating electroresponsiveness of mammalian inferior olivary neurons in vitro. J. Physiol. Lond. 315: 569-584, $1981 \mathrm{~b}$.

Matsumura, M., Kojima, J., Gardiner, T. W., and Hikosaka, O. Visual and occulomotor functions of the monkey subthalamic nucleus. $J$. Neurophysiol. 67: 1615-1632, 1992.

Meibach, R. C. and Katzman, R. Catecholaminergic innervation of the subthalamic nucleus: evidence for a rostral condition of the A9 (substantia nigra) dopaminergic cell group. Brain Res. 173: 364-368, 1979.

Miller, W. C. AND DeLoNG, M. R. Altered tonic activity of neurons in the globus pallidus and subthalamic nucleus in the primate MPTP model of parkinsonism. In: The Basal Ganglia II, edited by M. B. Carpenter and A. Jayaraman. New York: Plenum, 1987, p. 415-427.

Mitchfill, I. J., Clarke, C. E., Boyce, S., Robertson, R. G., Peggs, D., SAMBROOK, M. A., AND CrossMAN, A. R. Neural mechanisms underlying parkinsonian symptoms based upon regional uptake of 2-deoxyglucose in monkeys exposed to 1-methyl-4-phenyl-1,2,3,6-tetrahydropyridine. Neuroscience 32: 213-226, 1989.

Mitchell, S. J., Richardson, R. T., BAKER, F. H., AND Delong, M. R. The primate globus pallidus: neuronal activity related to direction of movement. Exp. Brain Res. 68: 491-505, 1987.
NAKANISHI, H., HoRI, N., AND KASTSUDA, N. Neostriatal evoked inhibition and the effects of dopamine on globus pallidus neurons in rat slice preparations. Brain Res. 358: 282-286, 1985.

NAMBU, A. AND LLINAS, R. Electrophysiology of the globus pallidus neurons: an in vitro study in guinea pig brain slices. Soc. Neurosci. Abstr. 16: $428,1990$.

Ohye, C., Saito, Y., Fukamachi, A., and Narabayashi, H. An analysis of the spontaneous rhythmic and non-rhythmic burst discharges in the human thalamus. J. Neurol. Sci. 22: 245-259, 1974.

Ohye, C., Shibazaki, T., Hirai, T., Wada, H., Hirato, M., and KawaSHIMA, Y. Further physiologic observations on the ventralis intermedius neurons in the human thalamus. $J$. Neurophysiol. 61: 488-500, 1989.

Paisley, A. C. ANd Summerlee, A. J. S. Relationships between behavioural states and activity of the cerebral cortex. Prog. Neurobiol. 22: 155-184, 1984.

Pare, D., Curro'Dossi, R., AND STeriade, M. Neuronal basis of the parkinsonian resting tremor: a hypothesis and its implications for treatment. Neuroscience 35: 217-226, 1990.

Parent, A., Lavoie, B., Smith, Y., AND Bedard, P. The dopaminergic nigropallidal projection in primates: distinct cellular origin and relative sparing in MPTP treated monkeys. In: Advances in Neurology edited by M. B. Streifler, A. D. Korczyn, E. Melamed, and M. B. H. Youdim. New York: Raven, 1990, vol. 53, p. 111-116.

PARENT, A. AND SMITH, Y. Differential dopaminergic innervation of the two pallidal segments in the squirrel monkey (Saimiri sciureus). Brain Res. 426: 397-400, 1987.

ReDmond, D. E., Roth, R. H., and Sladek, J. R. MPTP produces classic parkinsonian syndrome in African green monkeys. Soc. Neurosci. Abstr. 11: 166,1985

RIACHI, N. J. AND HARIK, S. I. Monoamine oxidases of the brains and livers of macaque and cercopitecus monkeys. Exp. Neurol. 115: 212217, 1992.

Rinvik, E., Grofova, I., Hammond, C., Feger, J., and Deniau, J. M. A study of the afferent connections to the subthalamic nucleus in the monkey and the cat using HRP technique. In: Advances in Neurology edited by A. J. Poirier, T. L. Sourkes, and P. J. Bedard. New York: Raven, 1979, vol. 24, p. 53-70.

Roeper, J., Hainsworth, A. II., ANd Ashcroft, F. M. Tolbutamide reverses membrane hyperpolarisation induced by activation of $\mathrm{D} 2$ receptors and $\mathrm{GABAB}$ receptors in isolated substantia nigra neurones. Pfluegers Arch. 416: 473-475, 1990.

SCHNEIDER, J. S. AND DACKO, S. Relative sparing of the dopaminergic innervation of the globus pallidus in monkeys made hemi-parkinsonian by intracarotid infusion. Brain Res. 556: 292-296, 1991.

SignORE, A. P., GODDARD, M., AND AEBISCHER, P. GABA delivery to the subthalamic nucleus alleviates MPTP induced hemiparkinsonism in non-human primates. Soc. Neurosci. Abstr. 19: 1051, 1993.

TATTON, W. G. AND LEE, R. G. Evidence for abnormal long-loop reflexes in rigid Parkinsonian patients. Brain Res. 100: 671-676, 1975.

TAYlor, J. R., Elsworth, J. D., Roth, R. H., SladeK, J. R., AND RedMOND, D. E., JR. Cognitive and motor deficits in the acquisition of an object retrieval/detour task in MPIP-treated monkeys. Brain 113:617$637,1990$.

TERZUOLO, C. A. AND ARAKI, T. An analysis of intra-versus extracellular potential changes associated with activity of single spinal motoneurons. Ann. NY Acad. Sci. 94: 547-558, 1961

TREMBlay, L., Filion, M., ANd BEdARD, P. J. Responses of pallidal neurons to striatal stimulation in monkeys with MPTP-induced parkinsonism. Brain Res. 498: 17-33, 1989.

VAllaR, L. AND MELDOLESI, J. Mechanisms of signal transduction at the dopamine D2 receptor. Trends Pharmacol. Sci. 10: 74-77, 1989.

Wichmann, T., Bergman, H., and Delong, M. R. Release of the subthalamic nucleus from gabaergic inhibition is an element in the development of parkinsonian signs. Soc. Neurosci. Abstr. 16: 239, 1990a.

Wichmann, T., Bergman, H., AND DeLONG, M. R. Increased neuronal activity in the subthalamic nucleus of MPTP treated monkeys (Abstract). Movement Disorders 5, Suppl. 1: 78, 1990b.

Wichmann, T., Bergman, H., AND Delong, M. R. The primate subthalamic nucleus. I. Functional properties in intact animals. J. Neurophysiol. 72: 494-506, 1994a.

Wichmann, T., Bergman, H., and Delong, M. R. The primate subthalamic nucleus. III. Changes in motor behavior and neuronal activity in the internal pallidum induced by subthalamic inactivation in the MPTP model of parkinsonism. J. Neurophysiol. 72: 521-530, 1994b. 